prospects of proposals such as quantum-interferometric optical lithography. The method can be adapted to generate entangled states of arbitrarily large photon number. Because prior entanglement is not required, the procedure would work well with singlephoton-on-demand sources ${ }^{29,30}$, which promise to be more efficient and scalable than down-conversion sources. Scalability would also be enhanced by the use of photon-number-resolving detectors. The construction proceeds from spatially separated, unentangled photons to a maximally entangled state in a single spatial mode, a state suitable for Heisenberg-limited phase measurements.

Received 22 December 2003; accepted 16 March 2004; doi:10.1038/nature02493.

1. Barish, B. C. \& Weiss, R. LIGO and the detection of gravitational waves. Phys. Today 52, 44-50 (1999).

2. Caron, B. et al. The Virgo interferometer. Class. Quantum Gravity 14, 1461-1469 (1997).

3. Holland, M. J. \& Burnett, K. Interferometric detection of optical-phase shifts at the Heisenberg limit. Phys. Rev. Lett. 71, 1355-1358 (1993)

4. Bollinger, J. J., Itano, W. M., Wineland, D. J. \& Heinzen, D. J. Optimal frequency measurements with maximally correlated states. Phys. Rev. A 54, R4649-R4652 (1996).

. Dowling, J. P. Correlated input-port, matter-wave interferometer: Quantum-noise limits to the atomlaser gyroscope. Phys. Rev. A 57, 4736-4746 (1998).

6. Ou, Z. Y. Fundamental quantum limit in precision phase measurement. Phys. Rev. A 55, 2598-2609 (1997).

7. Campos, R. A., Gerry, C. C. \& Benmoussa, A. Optical interferometry at the Heisenberg limit with twin Fock states and parity measurements. Phys. Rev. A 68, 023810 (2003).

8. D'Angelo, M., Chekhova, M. V. \& Shih, Y. Two-photon diffraction and quantum lithography. Phys. Rev. Lett. 87, 013602 (2001)

9. Sackett, C. A. et al. Experimental entanglement of four particles. Nature 404, 256-259 (2000).

10. Rauschenbeutel, A. et al. Step-by-step engineered multiparticle entanglement. Science 288, 2024-2028 (2000).

11. Zhao, Z. et al. Experimental violation of local realism by four-photon Greenberger-Horne-Zeilinger entanglement. Phys. Rev. Lett. 91, 180401 (2003).

12. Kok, P., Lee, H. \& Dowling, J. P. Creation of large-photon-number path entanglement conditioned on photodetection. Phys. Rev. A 65, 052104 (2002).

13. Fiurasek, J. Conditional generation of n-photon entangled states of light. Phys. Rev. A 65, 053818 (2002).

14. Pryde, G. J. \& White, A. G. Creation of maximally entangled photon-number states using optical fiber multiports. Phys. Rev. A 68, 052315 (2003).

15. Hofmann, H. F. Generation of highly non-classical n-photon polarization states by super-bunching a a photon bottleneck. Preprint at 〈http:/arxiv.org/quant-ph/0311198〉 (2003).

16. Knill, E., Laflamme, R. \& Milburn, G. J. A scheme for efficient quantum computation with linear optics. Nature 409, 46-52 (2001).

17. Franson, J. D., Donegan, M. M., Fitch, M. J., Jacobs, B. C. \& Pittman, T. B. High-fidelity quantum logic operations using linear optical elements. Phys. Rev. Lett. 89, 137901 (2002).

18. Resch, K. J., Lundeen, J. S. \& Steinberg, A. M. Conditional-phase switch at the single-photon level. Phys. Rev. Lett. 89, 037904 (2002).

19. Mitchell, M. W., Ellenor, C. W., Schneider, S. \& Steinberg, A. M. Diagnosis, prescription, and prognosis of a Bell-state filter by quantum process tomography. Phys. Rev. Lett. 91, 120402 (2003).

20. O'Brien, J. L., Pryde, C. J., White, A. G., Ralph, T. C. \& Branning, D. Demonstration of an all-optical quantum controlled-NOT gate. Nature 426, 264-267 (2003).

21. Sanders, B. C., Milburn, G. J. \& Zhang, Z. Optimal quantum measurements for phase-shift estimation in optical interferometry. J. Mod. Opt. 44, 1309-1320 (1997).

22. Huelga, S. F. et al. Improvement of frequency standards with quantum entanglement. Phys. Rev. Lett. 79, 3865-3868 (1997)

23. Rarity, J. G. et al. 2-photon interference in a Mach-Zehnder interferometer. Phys. Rev. Lett. 65, 1348-1351 (1990)

24. Ou, Z. Y., Zou, X. Y., Wang, L. J. \& Mandel, L. Experiment on nonclassical 4th-order interference. Phys. Rev. A 42, 2957-2965 (1990).

25. Meyer, V. et al. Experimental demonstration of entanglement-enhanced rotation angle estimation using trapped ions. Phys. Rev. Lett. 86, 5870-5873 (2001).

26. Rarity, J. C. \& Tapster, P. R. Three-particle entanglement from entangled photon pairs and a weak coherent state. Phys. Rev. A 59, R35-R38 (1999).

27. Rarity, J. G., Tapster, P. R. \& Loudon, R. Nonclassical interference between independent sources. Preprint at $\langle$ http:/arxiv.org/quant-ph/9702032〉 (1997).

28. Takeuchi, S. Beamlike twin-photon generation by use of type II parametric downconversion. Opt. Lett. 26, 843-845 (2001).

29. Michler, P. et al. A quantum dot single-photon turnstile device. Science 290, 2282-2285 (2000)

30. Solomon, G. S., Pelton, M. \& Yamamoto, Y. Single-mode spontaneous emission from a single quantum dot in a three-dimensional microcavity. Phys. Rev. Lett. 86, 3903-3906 (2001).

Acknowledgements We thank K. Resch and J. O'Brien for discussions, and J. Dowling and D. R. Schmulian for inspiration. This work was supported by the National Science and Engineering Research Council of Canada, Photonics Research Ontario, the Canadian Institute for Photonic Innovations and the DARPA-QuIST program.

Competing interests statement The authors declare that they have no competing financial interests.

Correspondence and requests for materials should be addressed to M.W.M.

(mitchell@physics.utoronto.ca).

\section{Increased seasonality in Middle East temperatures during the last interglacial period}

\author{
Thomas Felis ${ }^{1,2}$, Gerrit Lohmann ${ }^{1,2}$, Henning Kuhnert ${ }^{2}$, \\ Stephan J. Lorenz ${ }^{3}$, Denis Scholz ${ }^{4}$, Jürgen Pätzold ${ }^{1,2}$, \\ Saber A. Al-Rousan ${ }^{5}$ \& Salim M. AI-Moghrabi ${ }^{5 *}$
}

\author{
${ }^{1}$ DFG Forschungszentrum Ozeanränder, ${ }^{2}$ Fachbereich Geowissenschaften, \\ Universität Bremen, 28359 Bremen, Germany \\ ${ }^{3}$ Max-Planck-Institut für Meteorologie, Modelle \& Daten, 20146 Hamburg, \\ Germany \\ ${ }^{4}$ Heidelberger Akademie der Wissenschaften, 69120 Heidelberg, Germany \\ ${ }^{5}$ Marine Science Station, University of Jordan \& Yarmouk University, \\ 77110 Aqaba, Jordan
}

* Present address: Aqaba Special Economic Zone Authority, 77110 Aqaba, Jordan

The last interglacial period (about 125,000 years ago) is thought to have been at least as warm as the present climate ${ }^{1}$. Owing to changes in the Earth's orbit around the Sun, it is thought that insolation in the Northern Hemisphere varied more strongly than today on seasonal timescales ${ }^{2}$, which would have led to corresponding changes in the seasonal temperature cycle ${ }^{3}$. Here we present seasonally resolved proxy records using corals from the northernmost Red Sea, which record climate during the last interglacial period, the late Holocene epoch and the present. We find an increased seasonality in the temperature recorded in the last interglacial coral. Today, climate in the northern Red Sea is sensitive to the North Atlantic Oscillation ${ }^{4,5}$, a climate oscillation that strongly influences winter temperatures and precipitation in the North Atlantic region. From our coral records and simulations with a coupled atmosphere-ocean circulation model, we conclude that a tendency towards the high-index state of the North Atlantic Oscillation during the last interglacial period, which is consistent with European proxy records ${ }^{6-8}$, contributed to the larger amplitude of the seasonal cycle in the Middle East.

The Arctic Oscillation/North Atlantic Oscillation (AO/NAO), the Northern Hemisphere's dominant mode of atmospheric variability, exerts a strong influence on mid- and high-latitude continental climate by modulating the strength of the subpolar westerlies at interannual to interdecadal timescales ${ }^{9,10}$. Previous work has shown that the northernmost Red Sea represents a location to study past AO/NAO-related atmospheric variability over the Northern Hemisphere, and that annually banded corals from this subtropical site provide proxy records of this variability over the past centuries ${ }^{4,5}$. This narrow, desert-enclosed ocean basin is influenced by midlatitude continental climate ${ }^{5,11}$ and is sensitive to atmospheric processes owing to a weak water column stratification ${ }^{12}$.

Two fossil coral colonies (Porites) were collected near Aqaba on the Jordanian coast of the Gulf of Aqaba, the northeastern extension of the northernmost Red Sea (Fig. 1a). Colony AQB-10-B was recovered from a canal cut into the modern reef flat, whereas colony AQB-3-A was collected from a complex of raised reef terraces. $\mathrm{X}$-radiographs revealed annual density bands and were used to identify areas within the colonies that appear to be unaffected by diagenetic alteration (Fig. 1b, c). X-ray diffraction analyses of these areas indicate an aragonite content of $98-99 \%$, and petrographic thin sections show only traces of secondary aragonite. The bimonthly resolution time series of both coral $\delta^{18} \mathrm{O}$ and $\delta^{13} \mathrm{C}$ (not shown) generated from these areas show clear annual cycles, suggesting that the sampled sections were not subject to major diagenetic alterations with respect to stable isotopes (see Methods and Supplementary Information). 
Radiocarbon dating indicates that coral AQB-10-B grew $2.9 \mathrm{kyr}$ ago during the late Holocene. The age of coral AQB-3-A is 121.9 $(+7.0 /-6.3) \mathrm{kyr}$, based on U-series dating including a correction for open-system behaviour. Additional uncertainty due to model assumptions is reflected in the larger age error compared to usual $\mathrm{U}$-series dating of corals $^{13}$ (see Methods). The latter coral grew during the last interglacial period, which, in the Middle East, is documented between 124 and $119 \mathrm{kyr}$ ago based on a U-series dated speleothem record of eastern Mediterranean climate $^{14}$, with the main peak at $122 \mathrm{kyr}$ coinciding with the coral's age.

The late Holocene and last interglacial corals provide bimonthly resolution $\delta^{18} \mathrm{O}$ time series for time windows of 98 and $44 \mathrm{yr}$, respectively. Multitaper method spectral analysis reveals significant variance at interannual periods of 5-6 yr in both records (Fig. 2c, d), which can be interpreted as an indication of AO/NAO-like atmospheric variability over the Northern Hemisphere at 2.9 and $122 \mathrm{kyr}$ ago. Similar variability is evident in the time series of a modern coral from the northernmost Red Sea (Fig. 2a), where it is strongly linked
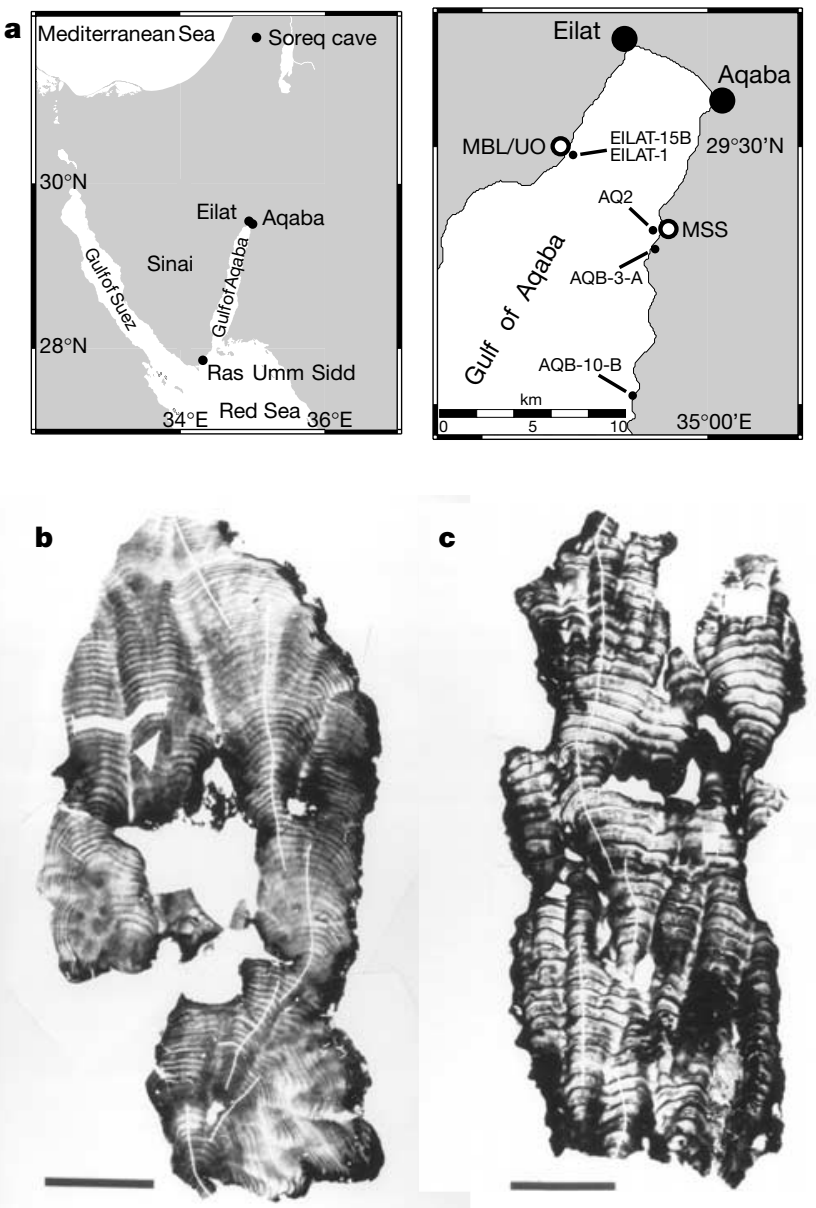

Figure 1 Maps of the northernmost Red Sea, and X-radiographs of the two fossil Porites corals. a, The sites of coral collection in the northern Gulf of Aqaba. Coral AQB-10-B was collected at $34^{\circ} 57.84^{\prime} \mathrm{E}, 29^{\circ} 22.91^{\prime} \mathrm{N}$; coral AQB-3-A was collected at $34^{\circ} 58.28^{\prime} \mathrm{E}$, $29^{\circ} 27.12^{\prime}$ N. MBL/UO, H. Steinitz Marine Biology Laboratory/Underwater Observatory, Eilat; MSS, Marine Science Station, Aqaba; sea surface temperature was measured at $U O^{25}$. b, c, X-radiograph positive prints of $5-m m$-thick slabs sliced parallel to the growth axis of coral AQB-10-B (b; 2.9 kyr) and coral AQB-3-A (c; $122 \mathrm{kyr})$. Alternating bands of high (dark colour) and low skeletal density (light colour) are visible. One year is represented by a high-density/low-density band pair. The sampling transect appears as a white line. The corals are about $60 \mathrm{~cm}$ high and $25-30 \mathrm{~cm}$ in diameter. Scale bars, $10 \mathrm{~cm}$. with regional sea surface temperature (SST) and the $\mathrm{AO} / \mathrm{NAO}^{4}$. Cross-spectral analysis reveals that this interannual variability is highly coherent and in phase with the AO index (Fig. 2b), although a minor fraction is associated with weaker and non-stationary tropical Pacific teleconnections modulated by higher-latitude atmospheric circulation ${ }^{4,11}$. Although the AO/NAO is most pronounced during winter, it is present throughout the year ${ }^{15,16}$. Consequently, spectral analyses were performed with bimonthly resolution time series, reflecting variability throughout the year. This procedure is supported by the finding that the physical mechanism that provides a link between the $\mathrm{AO} / \mathrm{NAO}$ and Middle East climate during winter ${ }^{5}$ is similar to that for interannual variability throughout the year (see Supplementary Fig. S1): a high-pressure anomaly over the Mediterranean Sea associated with the AO/NAO favours an anticyclonic flow of surface winds in the eastern Mediterranean, which results in advection of colder air from southeastern Europe, controlling SST and coral $\delta^{18} \mathrm{O}$ variability in the northern Red Sea ${ }^{5}$.

The most striking feature of the coral $\delta^{18} \mathrm{O}$ time series is increased seasonality in the last interglacial record compared to the modern and late Holocene records (Fig. 2). Because coral $\delta^{18} \mathrm{O}$ is influenced by both temperature and $\delta^{18} \mathrm{O}$ of sea water, we applied the coral $\mathrm{Sr} / \mathrm{Ca}$ palaeothermometer to the fossil corals and to three modern reference corals. Combined $\mathrm{Sr} / \mathrm{Ca}$ and $\delta^{18} \mathrm{O}$ analyses on modern corals show that both proxies satisfactorily document the seasonal
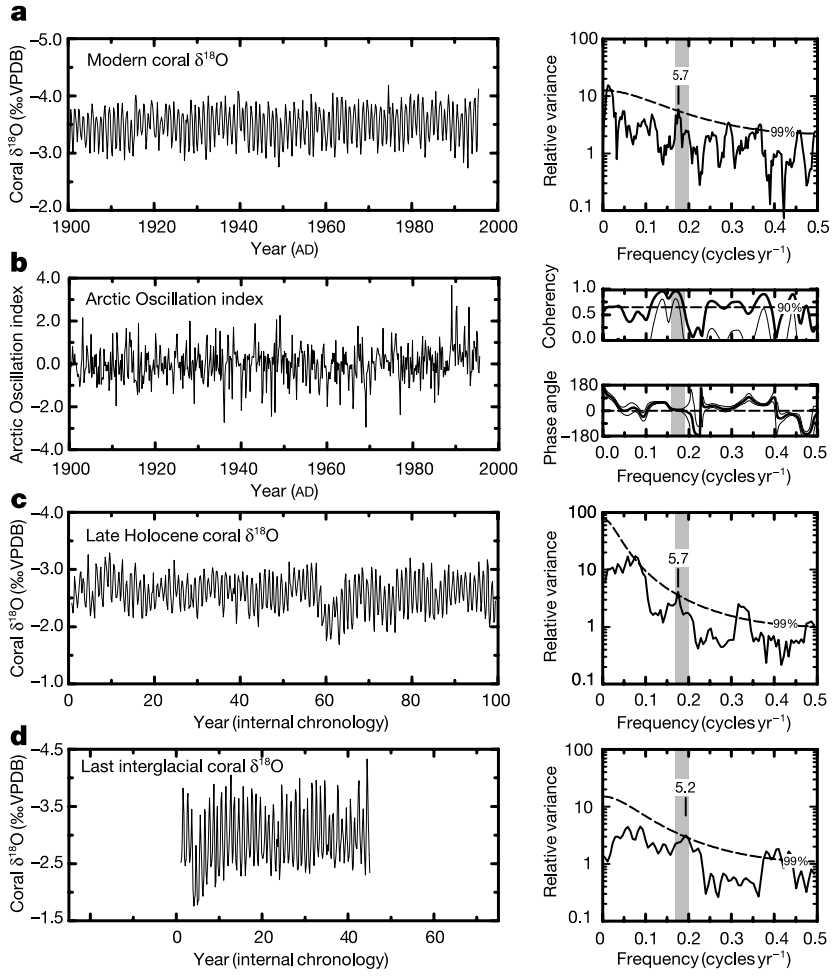

Figure 2 Time series of coral $\delta^{18} 0$ based on modern, late Holocene, and last interglacial Porites colonies from the northernmost Red Sea and their spectral properties. Bimonthly coral $\delta^{18} 0$ time series (left panel) and results of multitaper method spectral analysis with red noise null hypothesis ${ }^{30}$ (number of tapers, 3; bandwidth parameter, 2; 99\% significance level is indicated) (right panel) for $\mathbf{a}$, a modern coral from Ras Umm Sidd ${ }^{4}$ (RUS-95, AD 1750-1995), c, a late Holocene coral (AQB-10-B, 2.9 kyr) and d, a last interglacial coral (AQB-3-A, $122 \mathrm{kyr}$ ) from Aqaba. b, Bimonthly time series of the Arctic Oscillation (A0) index ${ }^{10}$ (left panel). Cross-spectral analysis between the time series of the modern coral and the AO index (right panel). The $90 \%$ confidence level for coherency is indicated. Spectral analyses were performed for bimonthly, detrended and normalized time series with the average seasonal cycle removed. 
SST cycle of $5.4^{\circ} \mathrm{C}$, indicating a seasonal cycle between 4.5 and $5.6^{\circ} \mathrm{C}$ (Fig. 3a), in agreement with earlier findings that $\delta^{18} \mathrm{O}$ seasonality in northern Red Sea corals is mainly controlled by temperature ${ }^{4}$. Both $\mathrm{Sr} / \mathrm{Ca}$ and $\delta^{18} \mathrm{O}$ of the late Holocene coral indicate a seasonal SST cycle of $5.2^{\circ} \mathrm{C}$ at $2.9 \mathrm{kyr}$ ago (Fig. $3 \mathrm{~b}$ ), similar to today. In contrast, in the last interglacial coral both proxies indicate increased SST seasonality of $8.4^{\circ} \mathrm{C}$ at $122 \mathrm{kyr}$ ago (Fig. 3d) (see Methods and Supplementary Information).

In order to understand the physical mechanisms responsible for increased SST seasonality in the northernmost Red Sea during the last interglacial, and seasonality similar to today at $2.9 \mathrm{kyr}$ ago, we performed coupled atmosphere-ocean general circulation model simulations (ECHO-G) for last interglacial, late Holocene, preindustrial, and modern conditions (see Methods). Consistent with coral-based results, the corresponding modelled SST indicates increased seasonality during the last interglacial, and seasonality similar to modern and pre-industrial conditions at $3 \mathrm{kyr}$ ago (Fig. 3c, e). Consistent with model-based SST, the modelled Middle East surface air temperature (SAT) anomalies indicate warmer summers and colder winters relative to modern conditions during the last interglacial (Fig. 4a, b). This increased seasonality would usually be explained by an amplified seasonal insolation cycle at that time (see Supplementary Fig. S4).

Indeed, our model suggests that warmer Middle East summers during the last interglacial result from increased summer insolation, as they are part of a spatially homogenous warming pattern over mid-latitude continental areas where insolation was enhanced (Fig. 4b). However, the model suggests that colder Middle East winters at that time did not solely result from reduced winter insolation at these latitudes, but are associated with the AO/NAO. The modelled winter SAT difference between last interglacial and modern climate reveals a warming and cooling pattern over the North Atlantic and adjacent continental areas that cannot be explained by differences in direct insolation forcing, but that resembles the spatial signature of the $\mathrm{AO} / \mathrm{NAO}^{9,10}$. This winter SAT anomaly indicates a tendency towards the AO/NAO highindex state during the last interglacial, with warmer winters in central Europe owing to increased advection of warm oceanic air
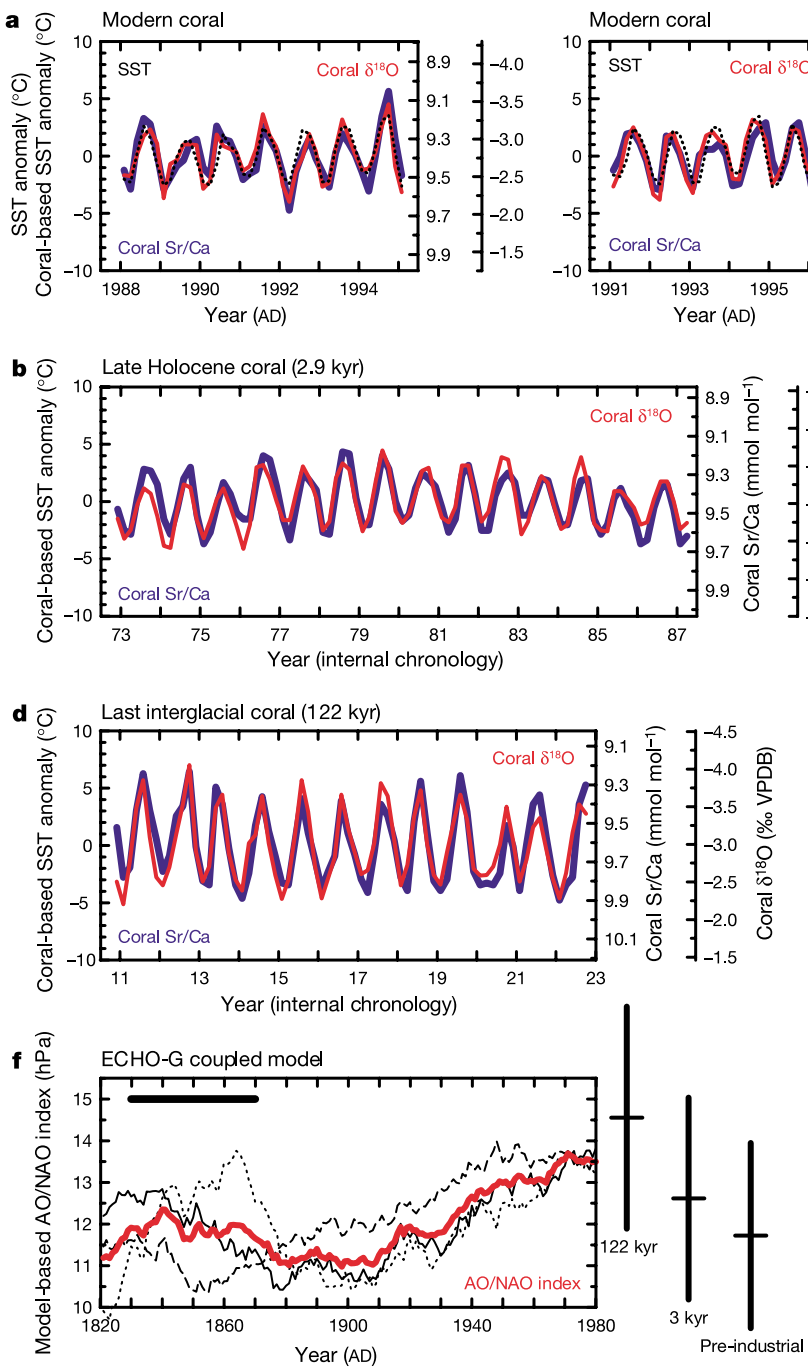
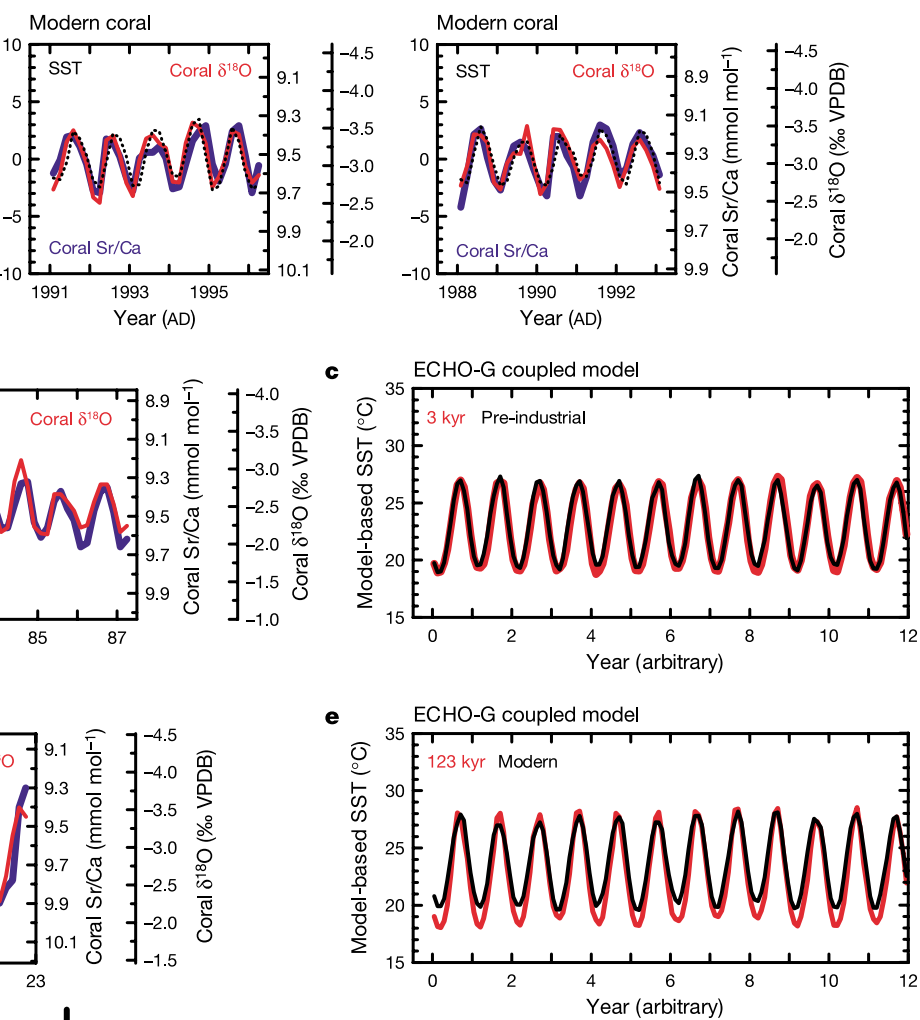

123 kyr (e, red), pre-industrial (around AD 1830; c, black) and modern conditions (around AD 1980; e, black). f, Modelled AO/NAO index (December-February). Three greenhouse gas scenarios (black lines) and the ensemble mean (red line) for the period $A D$ 1800-2000 (centred 41-yr running means). Mean standard deviations for 41 winters centred at $122 \mathrm{kyr}, 3 \mathrm{kyr}$ and the pre-industrial period (thick horizontal bar) are shown on

the right. See Supplementary Fig. S7 for index definitions.
Figure 3 Coral-based sea surface temperature (SST) anomalies for the northernmost Red Sea and ECHO-G model-based SST and AO/NAO indices. Bimonthly Porites coral $\delta^{18} \mathrm{O}$ (red) and Sr/Ca (blue) time series and coral-based SST anomalies (respective mean was subtracted). a, Modern corals EILAT-15B (left), AQ2 (centre), ElLAT-1 (right), in situ $\mathrm{SST}^{25}$ (dotted line); $\mathbf{b}$, late Holocene (AQB-10-B; $2.9 \mathrm{kyr}$ ) and $\mathbf{d}$, last interglacial coral (AQB-3-A; 122 kyr). c, e, Modelled monthly SST index of the coral region for $3 \mathrm{kyr}$ (c, red), 
from the west, and colder winters in the Middle East owing to increased advection of cold continental air from the north (Fig. 4a). This implies that the AO/NAO contributed to increased SST seasonality in the northernmost Red Sea during the last interglacial through winter cooling. This is consistent with (1) coral-based results of $\mathrm{AO} / \mathrm{NAO}-$ like interannual variability during the last
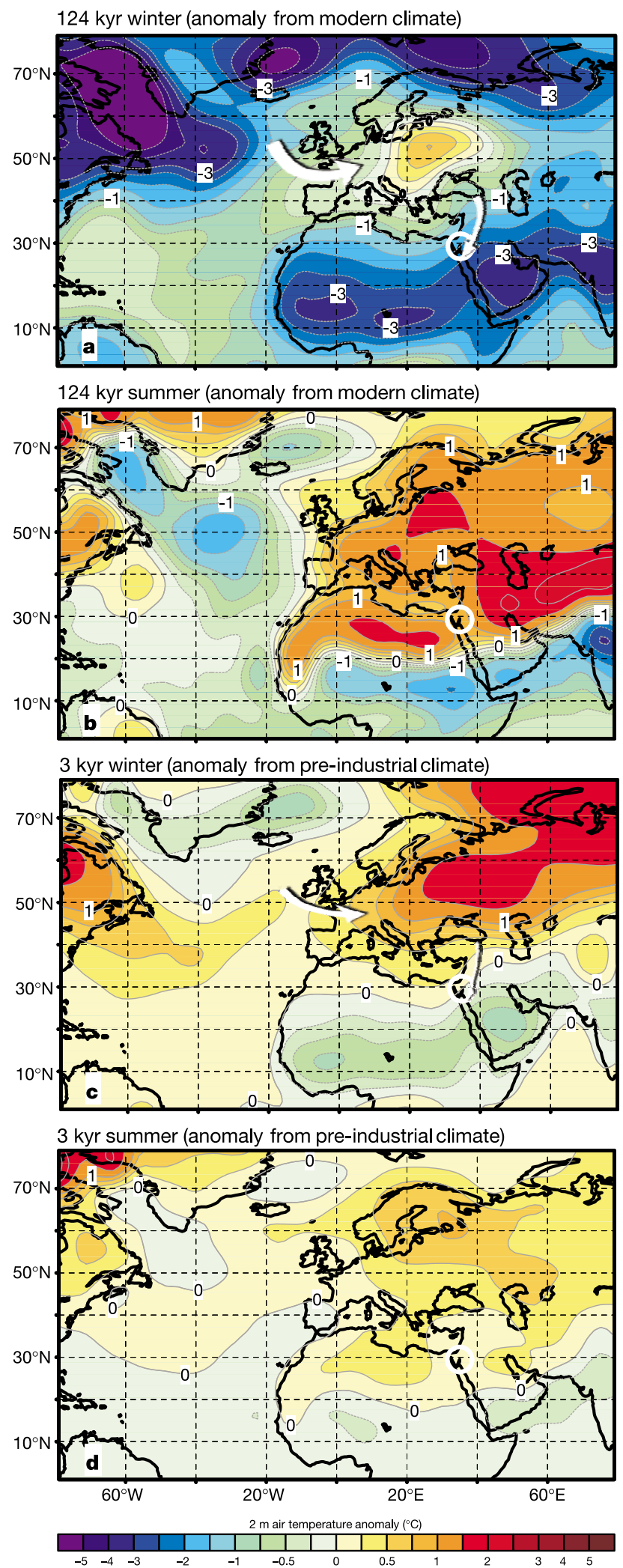

interglacial, (2) observations during recent decades where a shift towards the high-index $\mathrm{AO} / \mathrm{NAO}$ is accompanied by colder winters in the northernmost Red Sea leading to increased seasonality, and (3) a strong relationship between interannual variability of modelled regional winter SST and the AO/NAO (see Supplementary Figs S5, S6). Furthermore, a tendency towards the high-index $\mathrm{AO} / \mathrm{NAO}$ provides an explanation for warmer winters in central Europe during the last interglacial, as indicated by terrestrial proxy climate records ${ }^{6-8}$, a finding in conflict with an explanation via reduced winter insolation at these latitudes.

Consistent with coral- and model-based SST, the modelled northernmost Red Sea SAT anomalies indicate seasonality similar to modern and pre-industrial conditions at $3 \mathrm{kyr}$ ago (Fig. $4 \mathrm{c}$, d). The winter SAT anomaly indicates a tendency towards the highindex $\mathrm{AO} / \mathrm{NAO}$ at $3 \mathrm{kyr}$ ago relative to pre-industrial conditions, which is less pronounced compared to the last interglacial. Compared to the latter, the amplified seasonal insolation cycle at $3 \mathrm{kyr}$ ago is also less pronounced (see Supplementary Fig. S4). For the last interglacial, the winter SAT anomaly from pre-industrial climate indicates a more pronounced tendency towards the high-index $\mathrm{AO} / \mathrm{NAO}$ compared to that from modern conditions (see Supplementary Fig. S8).

The modelled SAT anomalies, as well as the modelled AO/NAO indices, suggest a combined response of the AO/NAO to seasonal insolation changes on orbital timescales and to atmospheric greenhouse gases (Fig. 3f). Consistent with other model-based studies $^{17,18}$, a greenhouse gas increase from pre-industrial to modern values results in a slight tendency towards the high-index AO/NAO. The pronounced last interglacial high-index $\mathrm{AO} / \mathrm{NAO}$ relative to 3 kyr ago and pre-industrial climate, however, can only be explained by differences in insolation forcing, as greenhouse gas concentrations were similar. Interestingly, the interannual $\mathrm{AO} / \mathrm{NAO}$ variability is nearly unaffected by the orbital forcing, consistent with coral-based results. The physical mechanism linking orbital forcing and the last interglacial high-index $\mathrm{AO} / \mathrm{NAO}$ most probably involves reduced boreal winter insolation in the tropics (Supplementary Fig. S4). In the model, this leads to a reduced pole-toequator temperature gradient, and a subsequent weakening of the Hadley cell accompanied by planetary wave activity, with increased Icelandic low and subtropical North Atlantic/eastern Mediterranean highs. The anomalous circulation pattern represents a quasi-equilibrium response to thermal forcing linked to land-sea temperature contrasts and orography ${ }^{19}$. Furthermore, a northward shift of the North American and Atlantic jet stream by downward propagating stratospheric anomalies is consistent with the highindex $\mathrm{AO} / \mathrm{NAO}^{10}$.

The AO/NAO, the dominant mode of Northern Hemisphere climate variability on interannual to interdecadal timescales ${ }^{9,10}$, has also been suggested to be important on millennial timescales ${ }^{20,21}$. In addition, our approach (of combining seasonal resolution coral proxy records from a climatically sensitive, exceptionally northern, subtropical reef site with coupled atmosphere-ocean circulation

Figure 4 Near-surface air temperature anomalies for the last interglacial and the late Holocene based on the coupled atmosphere-ocean general circulation model ECHO-G. Difference between last interglacial (124 kyr) and modern climate (AD 1975-85) for $\mathbf{a}$, winter (December, January, February; DJF) and b, summer (June, July, August; JJA). The corresponding anomalies from pre-industrial climate are shown in Supplementary Fig. S8. Difference between late Holocene (3 kyr) and pre-industrial climate (AD 1820-50) for $\mathbf{C}$, winter (DJF) and $\mathbf{d}$, summer (JJA). The corresponding anomalies from modern climate are shown in Supplementary Fig. S9. Near surface wind anomaly is schematically represented as white arrows. An average of 11 simulation years has been applied to the last interglacial and late Holocene climate centred at the respective time period. The region of coral collection in the northernmost Red Sea is marked by a white circle. 
model simulations) suggests an important role of the $\mathrm{AO} / \mathrm{NAO}$ in modulating regional Northern Hemisphere climate patterns and seasonality on orbital timescales. The cross-validation of well-dated, high-resolution palaeoclimatic records and state-of-the-art climate models provides a strong tool for evaluating the sensitivity of different modes of climate variability to natural and anthropogenic forcing factors. This provides a crucial step in understanding and predicting pronounced changes in past, present and future climate.

\section{Methods}

\section{Microsampling, oxygen isotope and $\mathrm{Sr} / \mathrm{Ca}$ analyses, age model}

Microsampling, $\delta^{18} \mathrm{O}$ analyses, age model construction, and interpolation to a bimonthly resolution were performed as recently described for a modern coral from the northernmost Red Sea ${ }^{4}$. The microdrill bit diameter was adapted to a coral's mean growth rate as estimated from X-radiographs in order to obtain at least six samples per year on average by continuous spot-sampling. For $\mathrm{Sr} / \mathrm{Ca}$ analyses, inductively coupled plasma mass spectrometry was used (see Supplementary Information).

\section{Radiocarbon and U-series dating}

An accelerator mass spectrometry (AMS) ${ }^{14} \mathrm{C}$ date of 3,290 $\pm 35 \mathrm{yr}$ before present (BP) was determined on coral AQB-10-B (KIA13708) at the Leibniz-Labor for Radiometric Dating and Isotope Research (Kiel, Germany). The ${ }^{14} \mathrm{C}$ age was converted to calendar age using the CALIB 4.3 calibration program ${ }^{22}$, yielding an age of 2,910 calibrated yr BP ( $2 \sigma$ range: $3,002-2,807 \mathrm{cal}$. yr BP). A $\Delta R$ value of $154 \mathrm{yr}$ was used to correct for regional differences in reservoir age, based on six AMS ${ }^{14} \mathrm{C}$ dates determined on two modern coral cores with established age models and data from the Marine Reservoir Correction Database (see Supplementary Table S1). Six thermal ionization mass spectrometry (TIMS) U-series dates were determined on coral AQB-3-A at the Forschungsstelle für Radiometrische Altersbestimmungen of the Heidelberger Akademie der Wissenschaften (Heidelberg, Germany).

The U-series ages range from 137.3 to $126.4 \mathrm{kyr}$ ago and the initial $\delta^{234} \mathrm{U}$ values are elevated, ranging from $215 \%$ to $385 \%$ and suggesting open-system behaviour of U-series isotopes. In order to solve this problem, a model approach was applied that yields an isochron age of $121.9(+7.0 /-6.3) \mathrm{kyr}(2 \sigma \text { range })^{13}$. The larger age error compared to usua U-series dating of corals arises from additional uncertainty due to the model assumptions. The age is consistent with peak sea-level conditions during the last interglacial, based on dated coral reef terraces from the Red Sea ${ }^{23}$ (136 to $118 \mathrm{kyr}$ ago) and elsewhere ${ }^{24}$ (128 to $121 \mathrm{kyr}$ ago), as well as with the last interglacial period in the Middle East ${ }^{14}$ (124 to $119 \mathrm{kyr}$ ago). Moreover, coral AQB-3-A was collected from a complex of raised reef terraces with an elevation in the range of other last interglacial reef terraces along the Red Sea coast ${ }^{23}$.

\section{Calibration of the proxies}

The seasonal maxima and minima in the Sr/Ca record of a modern coral (EILAT-15B) were tied to the corresponding extreme values in a monthly record of in situ SST ${ }^{25}$. A linear least-squares regression was then carried out for bimonthly interpolated Sr/Ca and SST data (with SST defined as the independent variable), giving a relationship of: $\mathrm{Sr} / \mathrm{Ca} \times 10^{3}=10.781( \pm 0.1181)-0.0597( \pm 0.00501) \times \operatorname{SST}\left(r^{2}=0.78\right)$. The slope of this regression equation is similar to that of calibrations at other locations ${ }^{26}$. The same procedure was applied to the coral $\delta^{18} \mathrm{O}$ record of EILAT-15B, giving a relationship of: $\delta^{18} \mathrm{O}=0.801( \pm 0.2773)-0.1514( \pm 0.01176) \times \operatorname{SST}\left(r^{2}=0.81\right)$. The slope is similar to that of a calibration from the region ${ }^{4}$

Using these equations to convert coral $\mathrm{Sr} / \mathrm{Ca}$ and $\delta^{18} \mathrm{O}$ to SST reveals large offsets in the coral-based mean SST between coral EILAT-15B and two other modern corals (AQ2, EILAT-1) for both proxies, most probably due to so-called vital effects. We therefore do not interpret coral Sr/Ca and $\delta^{18} \mathrm{O}$ in terms of absolute SST, but quantitative estimates of the range of the seasonal SST cycle are possible, as the slope of the proxy-SST calibrations remains unaffected. Modern coral $\delta^{18} \mathrm{O}$ data are from ref. 27 , age models were constructed according to ref. 4 .

\section{Global circulation model and experimental set-up}

The coupled atmosphere-ocean general circulation model ECHO-G is applied ${ }^{28}$. The atmospheric part of ECHO-G is the general circulation model ECHAM4 with its T30 resolution, which corresponds to a gaussian longitude-latitude grid of approximately $3.8^{\circ} \times 3.8^{\circ}$. ECHAM4 is coupled to the HOPE ocean model including a dynamicthermodynamic sea-ice model. ECHO-G was adapted to account for the influence of variations in the annual distribution of solar radiation resulting from the varying orbital parameters $^{29}$, which were calculated after ref. 2. The timescale of the astronomical forcing was shortened by an acceleration factor of 100 to enable simulations of a $>100$ kyr period with $\mathrm{ECHO}-\mathrm{G}^{29}$. The insolation trends of the last $140 \mathrm{kyr}$ are represented in 1,400 simulation years. Three ensemble experiments for the period $140 \mathrm{kyr}$ ago to AD 1800 were performed with orbital forcing ${ }^{2}$ only. Throughout the experiments, the greenhouse gas concentrations were fixed (latest Holocene values: 280 p.p.m. $\mathrm{CO}_{2}, 700$ p.p.b. $\mathrm{CH}_{4}$, 265 p.p.b. $\mathrm{N}_{2} \mathrm{O}$ ) and modern values for vegetation, sea level, and distribution of land, ocean and continental ice were used. The experiments were continued from AD 1800 onward with increasing greenhouse gas concentrations, reaching 370 p.p.m. $\mathrm{CO}_{2}$ in $\mathrm{AD}$ 2000. The temperature anomalies induced by anthropogenic greenhouse gases are shown in Supplementary Fig. S10.
Received 30 January; accepted 5 April 2004; doi:10.1038/nature02546.

1. Kukla, G. J. et al. Last interglacial climates. Quat. Res. 58, 2-13 (2002).

2. Berger, A. L. Long-term variations of daily insolation and Quaternary climatic changes. J. Atmos. Sci. 35, 2362-2367 (1978)

3. Montoya, M., von Storch, H. \& Crowley, T. J. Climate simulation for $125 \mathrm{kyr}$ BP with a coupled oceanatmosphere general circulation model. J. Clim. 13, 1057-1072 (2000)

4. Felis, T. et al. A coral oxygen isotope record from the northern Red Sea documenting NAO, ENSO, and North Pacific teleconnections on Middle East climate variability since the year 1750. Paleoceanography 15, 679-694 (2000)

5. Rimbu, N., Lohmann, G., Felis, T. \& Pätzold, J. Arctic Oscillation signature in a Red Sea coral. Geophys. Res. Lett. 28, 2959-2962 (2001).

6. Zagwijn, W. H. An analysis of Eemian climate in western and central Europe. Quat. Sci. Rev. 15, 451-469 (1996).

7. Aalbersberg, G. \& Litt, T. Multiproxy climate reconstructions for the Eemian and early Weichselian. J. Quat. Sci. 13, 367-390 (1998).

8. Klotz, S., Guiot, J. \& Mosbrugger, V. Continental European Eemian and early Würmian climate evolution: comparing signals using different quantitative reconstruction approaches based on pollen. Glob. Planet. Change 36, 277-294 (2003).

9. Hurrell, J. W. Decadal trends in the North Atlantic Oscillation: Regional temperatures and precipitation. Science 269, 676-679 (1995).

10. Thompson, D. W. J. \& Wallace, J. M. Regional climate impacts of the Northern Hemisphere Annular Mode. Science 293, 85-89 (2001)

11. Rimbu, N., Lohmann, G., Felis, T. \& Pätzold, J. Shift in ENSO teleconnections recorded by a northern Red Sea coral. J. Clim. 16, 1414-1422 (2003).

12. Eshel, G., Schrag, D. P. \& Farrell, B. F. Troposphere-planetary boundary layer interaction and the evolution of ocean surface density: Lessons from Red Sea corals. J. Clim. 13, 339-351 (2000)

13. Scholz, D., Mangini, A. \& Felis, T. U-series dating of diagenetically altered fossil reef corals. Earth Planet. Sci. Lett. 218, 163-178 (2004).

14. Bar-Matthews, M., Ayalon, A. \& Kaufman, A. Timing and hydrological conditions of sapropel events in the Eastern Mediterranean, as evident from speleothems, Soreq cave, Israel. Chem. Geol. 169, $145-156$ (2000).

15. Barnston, A. G. \& Livezey, R. E. Classification, seasonality and persistence of low-frequency atmospheric circulation patterns. Mon. Weath. Rev. 115, 1083-1126 (1987).

16. Rogers, J. C. \& McHugh, M. J. On the separability of the North Atlantic oscillation and Arctic oscillation. Clim. Dyn. 19, 599-608 (2002).

17. Fyfe, J. C., Boer, G. J. \& Flato, G. M. The Arctic and Antarctic Oscillations and their projected changes under global warming. Geophys. Res. Lett. 26, 1601-1604 (1999).

18. Shindell, D. T., Miller, R. L., Schmidt, G. A. \& Pandolfo, L. Simulation of recent northern winter climate trends by greenhouse-gas forcing. Nature 399, 452-455 (1999).

19. Held, I. M., Ting, M. \& Wang, H. Northern winter stationary waves: theory and modeling. J. Clim. 15, 2125-2144 (2002).

20. Keigwin, L. D. \& Pickart, R. S. Slope water current over the Laurentian Fan on interannual to millennial time scales. Science 286, 520-523 (1999).

21. Noren, A. J., Bierman, P. R., Steig, E. J., Lini, A. \& Southon, J. Millennial-scale storminess variability in the northeastern United States during the Holocene epoch. Nature 419, 821-824 (2002).

22. Stuiver, M. \& Reimer, P. J. Extended ${ }^{14} \mathrm{C}$ database and revised CALIB radiocarbon calibration program. Radiocarbon 35, 215-230 (1993).

23. Walter, R. C. et al. Early human occupation of the Red Sea coast of Eritrea during the last interglacial. Nature 405, 65-69 (2000).

24. Stirling, C. H., Esat, T. M., Lambeck, K. \& McCulloch, M. T. Timing and duration of the Last Interglacial: evidence for a restricted interval of widespread coral reef growth. Earth Planet. Sci. Lett. 160, 745-762 (1998).

25. Genin, A., Lazar, B. \& Brenner, S. Vertical mixing and coral death in the Red Sea following the eruption of Mount Pinatubo. Nature 377, 507-510 (1995).

26. Marshall, J. F. \& McCulloch, M. T. An assessment of the $\mathrm{Sr} / \mathrm{Ca}$ ratio in shallow water hermatypic corals as a proxy for sea surface temperature. Geochim. Cosmochim. Acta 66, 3263-3280 (2002).

27. Felis, T., Pätzold, J. \& Loya, Y. Mean oxygen-isotope signatures in Porites spp. corals: inter-colony variability and correction for extension-rate effects. Coral Reefs 22, 328-336 (2003).

28. Legutke, S. \& Voss, R. The Hamburg Atmosphere-Ocean Coupled Circulation Model Echo-G (Technical Report No. 21, Deutsches Klimarechenzentrum, Hamburg, Germany, 1999).

29. Lorenz, S. J. \& Lohmann, G. Acceleration technique for Milankovitch type forcing in a coupled atmosphere-ocean circulation model: method and application for the Holocene. Clim. Dyn. (submitted).

30. Ghil, M. et al. Advanced spectral methods for climatic time series. Rev. Geophys. 40, doi:10.1029/ 2001RG000092 (2002)

Supplementary Information accompanies the paper on www.nature.com/nature.

Acknowledgements We thank M. Segl and her team for stable isotope analyses, A. Abu-Hilal and the Aqaba Marine Science Station for support within the Red Sea Programme, N. Rimbu for discussions, M. Zuther for X-ray diffraction analyses, N. Zatloukal for thin sections, J. Zinke for material, W. Hale for comments, and S. Legutke for support with the ECHO-G model. This work was supported by Bundesministerium für Bildung und Forschung through KIHZ and DEKLIM, and by Deutsche Forschungsgemeinschaft through DFG Research Centre 'Ocean Margins' at Bremen University.

Competing interests statement The authors declare that they have no competing financial interests.

Correspondence and requests for materials should be addressed to T.F

(tfelis@allgeo.uni-bremen.de). The data that we report here can be accessed at the World Data Centers for Marine Environmental Sciences (www.wdc-mare.org/

PangaVista?query=@Ref25611) or Paleoclimatology (www.ngdc.noaa.gov/paleo/pubs/felis2004/ felis2004.html). 